\title{
A MEDIAÇÃO NA PRÁTICA ESCOLAR DO PIBID DE EDUCAÇÃO FÍSICA UEM-PR
}

\author{
LA MEDIACIÓN EN LA PRÁCTICA ESCOLAR DEL PIBID DE EDUCACIÓN FÍSICA EN \\ LA UEM-PR
}

\section{MEDIATION IN THE SCHOOL PRACTICE FROM THE PHYSICAL EDUCATION PIBID AT UEM-PR}

DOI: http://dx.doi.org/10.9771/gmed.v12i1.31838

Gustavo Borges Monteiro ${ }^{1}$

Carlos Henrique Ferreira Magalhães ${ }^{2}$

\begin{abstract}
Resumo: O presente artigo é uma investigação sobre a prática escolar do PIBID de educação física da UEM-PR em 2017, e teve como objetivo analisar as mediações da prática escolar desse programa. Para tanto, foi feito um levantamento de todos os relatos de aula de uma turma. A partir desse levantamento, foram feitas as categorizações empíricas e analíticas dos relatos de aula para interpretação qualitativa dos mesmos. Ao final da investigação, concluímos que a prática escolar do PIBID de educação física da UEM-PR foi objetivada a partir de mediações pedagógicas dialéticas, tendo as suas aulas sempre um ponto de partida e um ponto de chegada. A transição foi marcada por mediações cujo elemento principal foi a exploração das contradições entre os polos imediato e mediato da mediação dialética (OLIVEIRA; ALMEIDA; ARNONI, 2007). Concluímos que este movimento dialético das mediações (SAVIANI, 2013) (OLIVEIRA; ALMEIDA; ARNONI, 2007) da prática escolar do PIBID foi objetivado devido a sua fundamentação em concepções críticas de educação e de educação física (SOARES et al, 1992).
\end{abstract}

Palavras-chave: Mediação Pedagógica. Educação Física Escolar. Prática Escolar.

Resumen: Este artículo es una investigación sobre la práctica escolar del PIBID de educación física de la UEM-PR en 2017, y tuvo como objetivo analizar las mediaciones de la práctica escolar de ese programa. Para ello, se hizo un levantamiento de todos los relatos de clase de una clase. A partir de ese levantamiento se hicieron las categorizaciones empíricas y analíticas de los relatos de clase para interpretación cualitativa de los mismos. Al final de la investigación, concluimos que la práctica escolar del PIBID de educación física de la UEM-PR fue objetivada a partir de mediaciones pedagógicas dialécticas, y que sus clases tuvieron siempre un punto de partida y un punto de llegada. La transición fue marcada por mediaciones cuyo elemento principal fue la exploración de las contradicciones entre los polos inmediato y mediato de la mediación dialéctica (OLIVEIRA; ALMEIDA; ARNONI, 2007). Concluimos que este movimiento dialéctico de mediaciones (SAVIANI, 2013) (OLIVEIRA; ALMEIDA; ARNONI, 2007) dentro de la práctica escolar realizada por PIBID fue objetivado debido a su fundamento en concepciones críticas de educación y educación física (SOARES et al, 1992).

Palabras clave: Mediación Pedagógica. Educación física escolar. Práctica escolar.

Abstract: This article is an investigation about the school practice performed by the Physical Education PIBID at UEM-PR in 2017 and the aim was to analyze the mediations within the school practices of this program. In order to do so, we went over all the class reports from a class. From that verification, we performed analytical and empirical categorizations of the class reports for the qualitative interpretation of the same. At the end of the investigation, we concluded that the school practice performed by the Physical Education PIBID at UEM-PR was objectified through dialectical, pedagogical mediations with their classes always having a starting point and a final stop. The transition was marked by mediations, whose main element was the exploration of the contradictions between the immediate and mediate poles of the dialectical mediation (OLIVEIRA; ALMEIDA; ARNONI, 2007). We concluded that this dialectical movement of mediations (SAVIANI, 2013) (OLIVEIRA; ALMEIDA; ARNONI, 2007) within the school practice performed by PIBID was objectified due to its grounding in critical conceptions of education and physical education (SOARES et al, 1992). 
Keywords: Pedagogical Mediation. School Physical Education. School Practice.

\section{Introdução}

O PIBID (Programa Institucional de Bolsas de Iniciação à Docência)33 (UEM-PR - 2014-2017) foi um programa financiado pela Coordenação de Aperfeiçoamento de Pessoal de Nível Superior (CAPES), disponibilizado nos cursos de licenciatura do Ensino Superior. Dentre os principais objetivos definidos pelo programa destaca-se: "Contribuir para a articulação entre teoria e prática necessárias à formação dos docentes, elevando a qualidade das ações acadêmicas nos cursos de licenciatura" (CAPES, 2008).

Entendemos que uma das premissas básicas do PIBID foi possibilitar práticas que operacionalizassem uma ou mais metodologias de ensino, as quais tivessem como objetivo o ensinar na escola pública.

Importante lembrar que existiam diversos grupos do programa dentro de uma mesma universidade e cada grupo possuía autonomia para desenvolver suas práticas escolares, desde que orientados pelos objetivos do PIBID/CAPES.

Diante disso, o PIBID de Educação Física da Universidade Estadual de Maringá teve como princípios teórico-metodológicos para objetivação de sua prática escolar os pressupostos da Pedagogia Histórico-Crítica (SAVIANI, 2013), da Educação Física Crítico-Superadora (SOARES et al, 1992); e também Davidov (1988), Elkonin (2009), Martins (2011), Duarte (1999) e Marx (2004).

A abordagem crítico-superadora propõe que o conhecimento constituidor da educação física escolar seja a Cultura Corporal como linguagem, isto é, a forma como o homem exterioriza as suas representações do mundo com a expressão corporal em formas como danças, esportes, jogos, lutas, ginásticas, mímicas, etc. (SOARES et al., 1992).

Assim, os jogos e esportes de rebater constituem-se em elementos da Cultura Corporal e, por essa razão, o Badminton e alguns jogos de rebater (Taco e Frescobol) foram definidos como conteúdos estruturantes para o planejamento anual do PIBID, os quais consideramos serem objetivações genéricas altamente desenvolvidas no que corresponde ao ato humano de rebater. Sendo assim, sua apropriação é fundamental para o desenvolvimento humano do ser social, uma vez que Duarte (1999) explica que a atividade humana constrói objetivações ao longo da história, desde objetos que classifica como stricto sensu, como linguagem, dialetos e relações humanas imediatas, até as formas mais elevadas de objetivações, como a ciência, filosofia e arte, e aqui incluímos a Cultura Corporal. Assim, para que cada indivíduo desenvolva sua humanidade, ele deve se apropriar dos resultados mínimos da atividade social exigidos na vida do sujeito de acordo com o contexto histórico vivido. Logo, toda atividade desenvolve o psiquismo (MARTINS, 2011), seja ela produtiva ou não.

O PIBID de educação física da UEM-PR atendeu aproximadamente cinco turmas em dois colégios públicos, com duplas ou trios de pibidianos ${ }^{4}$ responsáveis por uma única turma durante todo o ano letivo. As aulas eram objetivadas com a supervisão da professora regente de cada turma. A rotina nos 
colégios consistia em uma hora de observação de aula da professora regente da turma, uma hora-aula de direção pelos pibidianos com supervisão da professora regente, três horas-aula de permanência por semana, as quais eram usadas para planejamento das aulas e relatos sobre as mesmas. Na universidade, eram dedicadas três horas semanais de estudos para a fundamentação teórica da prática escolar e laboratórios de expressão corporal.

O Badminton estava em todos os planejamentos, porém o grau de complexidade desse conteúdo dependeu do nível de desenvolvimento psíquico geral dos alunos em cada série.

A partir dessa breve exposição sobre os fundamentos do programa e da metodologia de ensino proposta pelo PIBID de educação física da UEM-PR, nos deparamos com a seguinte questão: A prática escolar objetivada pelo PIBID de educação física da UEM-PR seguiu os pressupostos de seu planejamento? Ou seja: suas mediações buscaram possibilitar a apropriação de determinado saber escolar pelos alunos?

Para poder responder essas questões fizemos o levantamento de relatos de aula e uma análise documental da turma $8^{\circ}$ ano $\mathrm{B}$ de um dos colégios da rede estadual de ensino do Paraná. Como método de categorização, utilizamos as indicações de Minayo (1992), realizando a categorização empírica dos relatos de aula e posteriormente a categorização analítica. Como técnica de interpretação, utilizamos a hermenêutica-dialética (MINAYO, 1992).

\section{Mediação: a contradição entre o imediato e mediato}

Para entender o sentido da mediação no desenvolvimento humano, necessitamos retomar a gênese do ser social. Para Marx (2013), o trabalho é categoria fundante do ser social. O homem, diferentemente dos outros animais, é o único ser que trabalha - ele adapta a natureza para si, por meio de sua intervenção e não apenas se adapta a ela instintivamente.

O homem está posto em um eterno intercâmbio de sua natureza interna (sua corporeidade) com as formas naturais externas. De modo consciente, ele tem uma necessidade, busca satisfazer tal necessidade e a objetiva na materialidade, tendo como resultado um objeto anteriormente inexistente na natureza. Assim, o homem modifica a natureza externa e ao mesmo tempo sua própria natureza, gerando um processo histórico de desenvolvimento da humanidade (MARX, 2013).

Ao objetivar a atividade fundante - quando o homem deixa de apenas se adaptar à natureza e passa a adaptá-la para si num processo dialético - ocorre o "despertar" da consciência, o homem planeja o ato em sua subjetividade e o objetiva na realidade. Leontiev (1978) explica que, dessa forma, o homem enquanto ser biológico superado dialeticamente no ser social tem o seu desenvolvimento liberto das leis biológicas, as quais regiam o desenvolvimento humano por meio da hereditariedade. Classificando como "a viragem", o autor relata que o desenvolvimento humano passou a ser regido por leis sócio-históricas, as aquisições humanas agora passam a ser fixadas nos instrumentos e não mais no código genético.

Para o autor, desde a viragem, ou salto ontológico, o sujeito nasce dotado das capacidades correspondentes à espécie, as quais permitem o desenvolvimento das capacidades genéricas humanas. 
Contudo, apenas nascer na espécie Homo sapiens sapiens não garante que o sujeito desenvolverá sua humanidade.

Mas, se o sujeito não recebe por hereditariedade as capacidades genéricas, como ele se apropria delas e as desenvolve? Para apropriar-se delas "o ser humano, deve entrar em relação com os fenômenos do mundo circundante através doutros homens, isto é, num processo de comunicação com eles. [...] Pela sua função, este processo é, portanto, um processo de educação" (LEONTIEV, 1978, p. 267).

Embora o autor não mencione a mediação e sim processo de educaşão, é nessa citação que se manifesta o ponto chave para compreendermos a necessidade das mediações. Segundo Oliveira; Almeida; Arnoni (2007, p. 108), “O processo educativo é constituído de mediações, portanto não pode haver educação sem que haja mediação." Maceno (2011, p. 45) classifica educação e mediação como parte de um mesmo todo - segundo ele, a educação "é uma mediação privilegiada entre o indivíduo e o gênero, ambos em contínua construção. É uma necessidade social para a constituição do indivíduo".

Ambos os autores entendem a mediação nesse sentido, pois tal processo educativo não é realizado apenas pela relação entre o aprendiz e os instrumentos, mas sim, são postas nele uma série de mediações nas quais os homens entram em contato com tais instrumentos (ou objetos) por meio de outros homens - mesmo porque os instrumentos em questão são produzidos pelos próprios homens enquanto sujeitos históricos.

Na relação entre o indivíduo e o gênero, Oliveira; Almeida; Arnoni (2007) discutem a mediação a partir das categorias singularidade, particularidade e universalidade. A singularidade nesse caso significa a individualidade do sujeito, isto é, as suas características próprias diferenciadas dos demais seres sociais. Entretanto, esse sujeito portador de uma singularidade não se descola da materialidade, estando, portanto, em contínua relação com a universalidade, isto é, o gênero humano, tornando-se semelhante a seus pares por conta dessa relação e o abstraindo na categoria ser social.

Essa relação entre ser singular e ser genérico deve ser compreendida em um movimento de negação recíproca. Essa negação é a particularidade, que é o movimento e estabelece a mediação entre esses polos. Ela é o ponto de convergência entre o singular e o geral que gera o desequilíbrio e a negação, permitindo a passagem/superação de um polo para o outro. Ainda que ela não seja o ponto central/médio - apesar de poder ocupá-lo - e não tenha um ponto fixo, sua localização depende de como se objetiva a materialidade de cada relação social.

A mediação não pode se confundir com uma mediação consensual, apaziguadora de conflitos. Pelo contrário, a mediação deve gerar contradição, negação, superação e movimento dialético entre dois polos opostos, distintos. Por gerar movimento é que a mediação dialética não pode ser entendida como ponto médio da contradição. O que esse movimento de negação permite são sínteses, a superação de um polo no outro. Esses polos correspondem ao imediato, que por meio da mediação pode vir a ser superado no mediato (OLIVEIRA; ALMEIDA; ARNONI, 2007).

Imediato e mediato são os polos pelos quais o movimento da mediação dialética transita. Eles são polos distintos, mas não antagônicos. O imediato está ligado ao que é, ao ser na sua forma imediata, 
enquanto o mediato corresponde ao vir a ser, aquilo de que o sujeito, por meio de um processo educativo constituído por mediações, pode se apropriar (Idem, Ibid.; 2007).

É preciso lembrar que essa relação correspondente à mediação dialética - trata-se de uma relação entre sujeitos. Portanto, nessa relação há sempre um sujeito, o qual se encontra no polo imediato, e outro, no mediato. Contudo, essa localização não é fixa: ela muda de acordo com a relação sobre o instrumento mediatizado. Por exemplo: em uma relação social entre pai e filho, o pai, quando ensina ao seu filho tarefas de manutenção da casa localiza-se, de início, no polo mediato do processo, e o filho no imediato. Enquanto em outro momento, quando o filho está ensinando seu pai a manusear ferramentas de um smartphone, o filho é quem ocupa, no início, o polo mediato, e o pai o polo imediato.

A superação do imediato no mediato ocorre quando o sujeito se apropria do objeto mediado na relação - podendo esse objeto ser conhecimento artístico, científico, filosófico, esportivo, laboral, etc. No exemplo acima, a superação do imediato no mediato pelo filho se dá quando este consegue realizar as tarefas de manutenção da casa sem a presença constante do pai. E a superação do imediato no mediato pelo pai ocorre quando este não necessita das instruções do filho para explorar todas as ferramentas de seu smartphone.

\section{A mediação dialética na prática escolar}

Até o momento, pudemos entender como os polos imediato e mediato se manifestam na generalidade das relações sociais. Cabe-nos agora aprofundar na particularidade da relação desses dois polos na especificidade da prática escolar. Segundo Silva Júnior \& Ferreti (2004, p. 109):

A prática escolar é uma prática social específica que se realiza na escola. [...] Uma dimensão dessa especificidade é constituída pelo contexto escolar de onde emerge o horizonte de possibilidades produzido pela síntese das dimensões institucional, organizacional e cultural específicas da escola.

Desse modo, a prática escolar carrega consigo elementos gerais de outras práticas sociais, assemelhando-se, por exemplo, à prática social familiar mencionada anteriormente. Contudo, a prática escolar - bem como outras - possui a sua especificidade, ou seja, ela se constitui de elementos culturais, institucionais e sócio-históricos que são determinantes em sua práxis. Dito de outro modo, essa prática não pode se confundir com atividades cotidianas de outras práticas sociais específicas.

A instituição escolar possibilita, por meio da prática, "momentos de suspensão", os quais podem conduzir os indivíduos a estabelecerem os nexos entre os diversos fenômenos do aparente e "heterogêneo" cotidiano escolar e compreendê-lo para além das relações automáticas e "imediatas" do cotidiano, estabelecendo como critério de verdade, não a "utilidade", mas a verdade para o gênero humano, com isso formandose na mesma direção e contexto. A instituição escolar, portanto, torna-se, na modernidade, uma esfera social privilegiada para a mediação entre a cotidianidade pragmática, na qual predomina a formação do indivíduo em-si, e a formação do indivíduo para-si. (Idem, Ibid., p.98) 
O em-si para-si são conceitos defendidos por Duarte (1999) que vão ao encontro da mediação dialética proposta por Oliveira; Almeida; Arnoni (2007). A formação pragmática do indivíduo em-si é aquela que não vai além do polo imediato da relação, enquanto a formação do indivíduo para-si é aquela que busca o mediato por meio do movimento gerado a partir da contradição. A instituição escolar é privilegiada à medida que possibilita a tensão sob a contradição entre a cotidianidade do aluno em-si, o imediato, com a não-cotidianidade do objeto mediatizado para-si, o mediato.

Oliveira; Almeida; Arnoni (2007) explicam que na particularidade do processo educativo na escola os alunos estão localizados no polo imediato da relação. Nesse caso, o imediato é o cotidiano dos estudantes. Quem está, ou deveria estar no plano mediato é o professor, que deve mediatizar o objeto de estudo.

Isto não implica em considerar o imediato dos alunos pobre ou inferior, mas sim diferente do mediato na relação da prática escolar e menos desenvolvido (considerando esta específica relação). Portanto, o professor é responsável por possibilitar a superação do primeiro polo no segundo, por meio da mediação.

Mas se o imediato não deve ser subestimado, por que ele deve ser superado? Para entendermos essa questão, é indispensável termos definido com clareza a especificidade da educação escolar. Saviani (2013) assevera que a escola se caracteriza por ser a instituição responsável pela transmissão-assimilação ${ }^{5}$ do saber escolar, ou seja, o papel do professor nessa relação é ensinar o saber escolar, sendo este saber escolar "a organização sequencial e gradativa do saber objetivo disponível numa etapa histórica determinada para efeito de sua transmissão-assimilação ao longo do processo de escolarização” (SAVIANI, 2013, p. 54).

Vejamos agora um trecho do relato de aula, cujo tema foi a acessibilidade do Tênis no Brasil:

Iniciamos a aula com uma das questões deixadas como tarefa: "Qual o preço de uma raquete de tênis?”. Os alunos apresentaram como raquete mais barata uma de $\mathrm{R} \$ 32,00$, e a mais cara custando $\mathrm{R} \$ 9.999,00$. Uma aluna questionou: "Mas quem compra uma raquete de R \$ 9.999,00?”. Retornamos à questão com “Quanto custa uma Ferrari? Tem gente que compra?” [...] Relacionamos os custos de materiais e manutenção com as poucas iniciativas públicas para o tênis, relacionando o porquê de se configurar como um esporte elitista. Perguntamos quais alternativas teríamos para mudar essa situação. Um aluno respondeu: "Criando várias instituições (com aulas de tênis)"; outro falou que há na cidade aulas grátis de outras modalidades: "É só querer". Partimos disso para problematizar outras questões como: "Basta a instituição com aulas grátis? E os materiais, transporte?” [...] Ao final, mostramos que essa era uma alternativa/via de se procurar uma mudança na situação do esporte, mas sem alterar a configuração da sociedade haveria sempre práticas inacessíveis para a maioria da população. (Relato de aula sobre a turma $8^{\circ} \mathrm{B}$ )

Observa-se o movimento dialético da mediação entre o imediato e mediato. Quando os pibidianos iniciaram a aula, retomaram a tarefa solicitada na aula anterior. A própria atividade de pesquisa em forma de tarefa para casa germina a contradição entre o imediato do cotidiano do aluno com o mediato representado pelos instrumentos (raquetes de tênis) objetivados na realidade. Basta vermos o espanto da aluna causado pelo choque com a imediaticidade de seu cotidiano. Aproveitando esse momento de necessidade de superação, os pibidianos fizeram uma relação com a universalidade da distribuição de renda mundial, a fim de possibilitar generalizações na subjetividade da estudante, de forma 
que ela relacione a particularidade com a generalidade, ou seja, estimulando uma superação na forma mediata.

Na sequência da aula, seguindo o momento metodológico de resgatar/registrar (OLIVEIRA; ALMEIDA; ARNONI, 2007), os pibidianos pediram para os alunos exporem suas impressões sobre a configuração do Tênis na sociedade capitalista. Percebe-se a partir daí que o imediato dos alunos é restrito à análise empírica fragmentada das partes, bem como aos valores burgueses subjacentes no esporte (SOARES et al., 1992). O imediato dos alunos foi confrontado pelos pibidianos por meio de problematizações (SAVIANI, 2013), (OLIVEIRA; ALMEIDA; ARNONI, 2007), gerando negação, contradição e necessidade de superação. Quando os pibidianos apresentaram a síntese final a respeito das determinações do modo de produção da vida humana nas demais esferas da sociedade (MARX, 2013), ela foi ao encontro das respostas que os estudantes contrariados pelas problematizações procuravam no campo mediato. Desse modo, percebe-se como o movimento da mediação dialética é transitório, podendo e devendo passar pelo plano imediato, mas sempre buscando as sínteses no mediato.

A relação com a configuração do esporte na sociedade capitalista e as mediações a respeito desse tema aparecem, pois as metodologias de ensino que fundamentaram a prática escolar do PIBID de educação física da UEM-PR propõem a necessidade de rompimento com os valores burgueses subjacentes no esporte de rendimento, tendo como conteúdo atravessador ao conteúdo estruturante do planejamento escolar a luta de classes (SOARES et al, 1992).

Abaixo seguem partes de um relato sobre o ensino de duas técnicas do Badminton:

Questionamos: “O que é rebater?” Surgiram respostas como: "Bater em algo novamente" e "Afastar algo que vem em sua direção". Dissemos a eles, então, que as definições que trouxeram também eram válidas, porém, dissemos que a definição que usaríamos seria que rebater compreende a ação de propulsão de um objeto, utilizando um implemento ou diretamente o próprio corpo [...], ou seja, o impulso dado a um objeto para que ele se desloque. Perguntamos novamente, agora sobre o que é forehand e backhand. De início os alunos não conseguiram responder. Lembramos, então, de aulas anteriores e apresentamos exemplos até alguns alunos conseguirem descrever corretamente os dois movimentos. Após isso, pedimos para que todos executassem os dois movimentos sem o uso de instrumentos. Problematizamos algumas falhas que observamos na execução de alguns alunos e, ao final da atividade, perguntamos se todos tinham consciência de como realizar os movimentos de forehand e backhand. Os alunos responderam afirmativamente [...] observamos diversos problemas na execução dos movimentos, como: controle de força na rebatida, percepção de espaço, pouca realização das técnicas propostas e, até mesmo problemas em acertar a bola [...] Com isso, observamos que os problemas não advinham apenas da falta de conhecimento das técnicas, mas também de uma expressão corporal extremamente empobrecida. Para encerrar a aula, nos reunimos no centro da quadra e realizamos problematizações novamente a respeito do backhand e forehand, sobre domínio corporal e qual técnica deveria ser utilizada em determinados momentos do jogo: identificamos muitas afirmações equivocadas sobre a utilização das técnicas, relacionando-as erradamente com as expressões corporais propostas. Identificamos também que poucos reconheciam a importância da movimentação de pernas, e muita dificuldade para formulação de sentenças, sendo a maioria das respostas a realização de algum movimento acompanhado por um "aquil". Explicamos para eles as implicações que a falta de domínio corporal traz, e a importância de seu desenvolvimento para a apropriação de objetivações em forma de cultura corporal, como os jogos de rebater, e a necessidade de que eles tenham consciência do que fazem, e que também expliquem teoricamente todas as suas práticas [...] também explicamos a eles novamente a respeito 
da utilização adequada do forehand e backhand nos jogos de rebater. (Relato de aula sobre a turma $8^{\circ} \mathrm{B}$ )

Novamente, os pibidianos utilizaram o resgatar/registrar (OLIVEIRA; ALMEIDA; ARNONI, 2007) para identificar o ponto de partida da aula, ou seja, os conceitos imediatos dos alunos. Os conceitos dos alunos faziam parte de sua prática cotidiana em-si, um conhecimento pragmático que não apreende o objeto em sua totalidade. À medida que os pibidianos mencionaram que os conceitos verbalizados pelos alunos eram válidos, mas ao mesmo tempo explicaram e exigiram o domínio do conceito científico sistematizado na particularidade da prática escolar, eles valorizaram o desenvolvimento psíquico dos alunos e para isso, também se fundamentaram no pressuposto de que o cotidiano dos alunos não é inferior, porém diferente, e na situação específica da prática escolar é menos desenvolvido (Idem, Ibid.). Contudo, ao mesmo tempo geraram a negação e contradição com o conceito imediato dos alunos, estimulando a reflexão crítica dos mesmos a respeito da compreensão do objeto de estudo dada no ponto de partida, a fim de se alcançar no ponto de chegada o mediato para-si.

Em um segundo momento, os pibidianos identificaram problemas de aprendizagem na objetivação das atividades sistematizadas. Ao não conseguirem desenvolver as proposições feitas pelos professores, os alunos se fatigaram em sua imediaticidade, ou seja, houve uma falha no movimento da mediação dialética. Quando os pibidianos identificaram tal problema e ressistematizaram sua prática, notamos uma atitude consciente e determinada a uma finalidade, que é a superação do imediato no mediato, ocorrendo uma preocupação explícita com o ensino, com a transmissão-apropriação do objeto de estudo. A forma como se objetivaram as problematizações das situações encontradas no decorrer da aula demonstra que os pibidianos, quando explicaram aos alunos a necessidade de conceituar as suas expressões corporais, realizaram a mediação a fim de que os alunos tivessem a apropriação real do objeto, isto é, a problematização do conceito científico em contraponto ao conceito espontâneo durante a atividade de expressão corporal das empunhaduras, provocando a atividade crítica dos alunos e levando-os a estabelecer generalizações a partir do saber mediatizado, não resultando, assim, em uma mera assimilação de palavras (MARTINS, 2011), mas sim no processo de apropriação do objeto posto na relação. Em síntese, identifica-se nesse relato que a aula sai de um ponto de partida imediato e é concluída em um ponto de chegada mediatizado, como propõem Oliveira; Almeida; Arnoni (2007) e Saviani (2013).

Observando os relatos, percebemos comprometimento dos pibidianos com o ensino sistematizado em suas mediações, seguindo sempre uma metodologia baseada no ponto de partida das aulas, resgatando o imediato e passando por sistematizações e problematizações, a fim de superá-lo em um estágio mediato mais desenvolvido - no ponto de chegada. Todavia, nota-se que diversas vezes suas sistematizações foram reestruturadas durante a aula, a partir da identificação de problemas de aprendizagem, ou seja, problemas no movimento da mediação entre os polos. Entendemos que essas identificações foram importantes avaliações feitas pelos pibidianos. Para exemplificar, selecionamos abaixo trechos de diversos relatos que apontam isso: 
Os alunos, entretanto, mesmo com essa adaptação não conseguiam se apropriar da técnica de rebatida do frescobol, onde identificamos os seus baixos níveis de expressão corporal. Nós, pibidianos, após insucessos em orientá-los apenas verbalmente, sentimos a necessidade de expor o modo de rebater visualmente. [...]

[...] Percebendo essa descontinuidade, acrescentamos uma nova atividade que consistia na formação de duas colunas $[\ldots]$

[...] percebemos então um déficit de atenção voluntária e raciocínio rápido, também a falta de agilidade, uma vez que não conseguiram mudar de direção com velocidade. Desse modo, partimos para a aplicação da próxima atividade, que é conhecida como "suicídio" e tem o intuito de desenvolver a agilidade e percepção de espaço. (Relato de aula sobre a turma $8^{\circ} \mathrm{B}$ )

Os excertos acima correspondem a três aulas diferentes. Contudo, em todas observamos algo em comum: há a identificação do problema e logo em seguida uma reestruturação da mediação pedagógica a fim de superá-lo. Essa identificação é um indispensável momento estruturante da mediação dialética, pois corresponde ao momento de avaliação (OLIVEIRA; ALMEIDA; ARNONI, 2007). Nos casos em que as avaliações identificaram resultados ineficientes, foi necessária uma reestruturação da atividade, como ocorrido nos casos relatados.

\section{Considerações Finais}

As mediações do PIBID na escola evidenciam uma preocupação basilar com o ensino, isto é, com a objetivação e apropriação do saber escolar. Houve um processo de educação sistematizada para o ensino da cultura corporal clássica na escola pública.

Importa-nos assinalar a importância dada pelos pibidianos ao ensinar, não em proporcionar vivências, mas sim na superação do imediato no mediato. A prática escolar no ensino da cultura corporal não pode e não deve se limitar a mera função de promover experiências ou estimular uma pseudocriatividade, sobretudo na escola pública. Uma vez que - como visto nos relatos acerca da prática do Tênis no Brasil - as condições objetivas dos alunos dessas instituições não favorecem a apropriação de elementos da cultura clássica fora do ambiente escolar.

A partir da análise dos relatos de aula do PIBID, foi possível observar a preocupação da superação do imediato (cotidiano dos alunos) no mediato (saber escolar), uma vez que em todos os trechos de relatos expostos aqui existe um caminho percorrido por meio de problematizações e sistematizações.

Essa sistematização de uma prática escolar por meio de mediações geradoras de movimento foi conquistada com a fundamentação do planejamento do grupo, baseada em metodologias de ensino críticas voltadas para a exploração das contradições inerentes à escola pública. Os relatos dos pibidianos demonstram a fidelidade do grupo às suas referências de metodologia de ensino. As objetivações dos pibidianos na turma analisada cumprem com elementos sistematizadores fundamentais de uma prática escolar fundamentada na Pedagogia Histórico-Crítica (SAVIANI, 2013) e na Educação Física Crítico-Superadora (SOARES et al., 1992). 
Dessa maneira, defendemos a importância do PIBID na formação de professores. Um dos maiores debates no meio acadêmico dos cursos de licenciatura é o de que os estudantes de graduação têm dificuldades em relacionar as concepções teóricas com a prática escolar, e acabam caindo no pragmatismo - em uma prática docente imediata. O PIBID de educação física da UEM-PR possibilitou uma prática escolar fundamentada em metodologias de ensino comprometidas com o ensinar na escola pública.

Assim, concluímos que a prática escolar do PIBID de educação física da UEM-PR nos oferece apontamentos de grande valia para a elaboração de uma prática escolar comprometida com a apropriação e objetivação dos saberes clássicos pelos alunos da escola pública. Suas mediações possibilitaram a superação do imediato no mediato por meio de contradições, sendo essa a forma mais adequada de se conceber a mediação da prática escolar em uma instituição que tem como objetivo a apropriação e objetivação do saber escolar.

\section{Referências:}

CAPES, Pibid. Pibid - Programa Institucional de Bolsa de Iniciação à Docência. Disponível em: <http://www.capes.gov.br/educacao-basica/capespibid/pibid>. Acesso em: 23 mar. 2018.

DAVÍDOV, V. V. La enseñanza escolar y el desarrollo psíquico. Moscú: Editorial Progreso, 1988.

DUARTE, Newton. A individualidade para si: contribuição a uma teoria histórico-social da formação do indivíduo. $-2^{\circ}$ Ed. - Campinas, SP: Autores Associados, 1999.

ELKONIN, D. B. Psicologia do jogo. 2 ed. São Paulo: Martins Fontes, 2009.

LEONTIEV, Alexis. O desenvolvimento do psiquismo: O homem e a cultura. Lisboa: Horizonte, 1978.

MACENO, Talvanes Eugênio. Educação e universalização no capitalismo. São Paulo: Baraúna, 2011.

MARTINS, Lígia Márcia. O desenvolvimento do psiquismo e a educação escolar: contribuições à luz da psicologia histórico cultural e da pedagogia histórico-crítica. 2011. 249 p. - Faculdade De Ciências, Universidade Estadual Paulista Júlio De Mesquita Filho, Bauru, 2011.

MARX, Karl. Manuscritos econômico-filosóficos. São Paulo: Boitempo, 2004.

MARX, Karl. O capital: crítica da economia política. Livro 1. São Paulo: Boitempo, 2013.

MINAYO, M. C. de S. O desafio do conhecimento: pesquisa qualitativa em saúde. São Paulo - Rio de Janeiro: HUCITEC-ABRASCO, 1992.

OLIVEIRA, Edilson Moreira de; ALMEIDA, José Luís Vieira de; ARNONI, Maria Eliza Brefere. Mediação dialética na educação escolar: teoria e prática. São Paulo: Loyola, 2007.

SAVIANI, Demerval. Pedagogia histórico-crítica: primeiras aproximações. 11 ed. Campinas: Autores Associados, 2013.

SILVA JÚNIOR, João dos Reis; FERRETI, Celso João. O institucional e a cultura da escola. São Paulo: Xamã, 2001.

SOARES, C. L. et al. Metodologia do ensino de Educação Física. São Paulo: Cortez, 1992. 


\section{Notas}

1 Licenciando em Educação Física pela UEM-PR. Currículo Lattes: http://lattes.cnpq.br/4260487713608774. Orcid: https://orcid.org/0000-0002-2353-1360.E-mail: gustavoborgesguastala@gmail.com.

2 Doutor em Educação pela UFSCar. Professor Associado da UEM-PR. Currículo Lattes: http://lattes.cnpq.br/2945866267836763. Orcid: https://orcid.org/0000-0001-9977-2497. E-mail: chfmagalhaes@uem.br.

3 Edital CAPES nº1/2013.

4 Acadêmicos participantes do PIBID de educação física da UEM-PR.

5 O conceito de assimilação do autor não se assemelha ao conceito de assimilação das concepções de educação Piagetianas.

Recebido em: 20.05.2019

Aprovado em: 25.09.2020 